\title{
Vitamin E-Loaded PLA- and PLGA-Based Core-Shell Nanoparticles: Synthesis, Structure Optimization and Controlled Drug Release
}

\author{
Norbert Varga ${ }^{1}$, Árpád Turcsányi ${ }^{1}$, Viktória Hornok ${ }^{1,2}$ (i) and Edit Csapó ${ }^{1,3, *(\mathbb{D}}$ \\ 1 Interdisciplinary Excellence Centre, Department of Physical Chemistry and Materials Science, \\ University of Szeged, Rerrich B. square 1, H-6720 Szeged, Hungary \\ 2 Department of Physical Chemistry and Materials Science, MTA Premium Post Doctorate Research Program, \\ University of Szeged, Rerrich B. Square 1, H-6720 Szeged, Hungary \\ 3 MTA-SZTE Biomimetic Systems Research Group, Department of Medical Chemistry, University of Szeged, \\ Dóm square 8, H-6720 Szeged, Hungary \\ * Correspondence: juhaszne.csapo.edit@med.u-szeged.hu; Tel.: +36-(62)-544-476
}

Received: 27 June 2019; Accepted: 16 July 2019; Published: 22 July 2019

check for updates

\begin{abstract}
The ( \pm )- $\alpha$-Tocopherol (TP) with vitamin E activity has been encapsulated into biocompatible poly(lactic acid) (PLA) and poly(lactide-co-glycolide) (PLGA) carriers, which results in the formation of well-defined nanosized ( $\sim 200-220 \mathrm{~nm}$ ) core-shell structured particles (NPs) with 15-19\% of drug loading (DL\%). The optimal ratios of the polymer carriers, the TP active drug as well as the applied Pluronic F127 (PLUR) non-ionic stabilizing surfactant, have been determined to obtain NPs with a TP core and a polymer shell with high encapsulation efficiency (EE\%) $(69 \%)$. The size and the structure of the prepared core-shell NPs as well as the interaction of the carriers and the PLUR with the TP molecules have been determined by transmission electron microscopy (TEM), dynamic light scattering (DLS), infrared spectroscopy (FT-IR) and turbidity studies, respectively. Moreover, the dissolution of the TP from the polymer NPs has been investigated by spectrophotometric measurements. It was clearly confirmed that increase in the EE\% from ca. 70\% (PLA/TP) to ca. 88\% (PLGA65/TP) results in the controlled release of the hydrophobic TP molecules (7 h, PLA/TP: 34\%; PLGA75/TP: 25\%; PLGA65/TP: 18\%). By replacing the PLA carrier to PLGA, ca. 15\% more active substance can be encapsulated in the core (PLA/TP: 65\%; PLGA65/TP: 80\%).
\end{abstract}

Keywords: vitamin E; tocopherol; PLA; PLGA; core-shell nanoparticles; drug delivery; controlled drug release

\section{Introduction}

The encapsulation of the pharmaceutical ingredients in a macro- or a nanocarrier is a key factor in nanomedicine developments [1-3]. Utilization of drug delivery systems can increase and prolong the efficiency of the active drugs. Due to the good biocompatibility and structural properties, several materials such as proteins and mostly biodegradable polymers, e.g., chitosan, alginate, hyaluronic acid, poly(lactide) or poly(lactic acid) (PLA), polycaprolactone (PCL), poly(trimetilene-carbonate) (PTMC), etc., have been widely used as potential carriers of the nanosized drug delivery systems [4-12]. Many types of PLA copolymers, such as poly(lactide-co-glycolide) (PLGA), polylactide-poly(ethylene glycol) (PLA-PEG), poly(caprolactone-ethylene glycol-lactide) (PCELA), etc., are also well-known as drug carriers [13-17]. As a result of copolymerization, the hydrophilicity of the PLA can be remarkably tuned, which opens the possibility of encapsulating active ingredients that have hydrophilic or hydrophobic character into the polymer matrix. 
The $( \pm)$ - $\alpha$-Tocopherol (TP) is one of the highest biological activity fat-soluble vitamins from the vitamin E family and is composed of eight tocopherols and tocotrienols (alpha $(\alpha)$, beta $(\beta)$, gamma $(\gamma)$ and delta ( $\delta$ ) isomers for both cases) [18]. Several studies focus on the encapsulation of the TP, because vitamin E can prevent and treat many chronic and age-related diseases, e.g., Alzheimer's disease [19]. Furthermore, the TP is described as functioning as an antioxidant, and the higher vitamin E content is associated with a lower risk of several cancer diseases (kidney, lung, bladder, etc.).

Alqahtani et al. synthesized TP-loaded PLGA50 NPs with an average size of ca. $130 \mathrm{~nm}$ using Polyvinyl alcohol (PVA) as a stabilizer, but only $4-4.5 \%$ of drug loading (in mg drug/100 mg PLGA) was achieved [20]. However, Zigoneanu and coworkers increased the TP loading to 8-16\% using the PLGA50 carrier and PVA and sodium dodecyl sulphate (SDS) surfactant stabilizing agents, but it was confirmed that the $86 \%$ of the drug dissolved for NPs (d 220-280 nm) with $8 \%$ TP loading, while $36 \%$ of the TP drug released from the NPs when the loading was $16 \%$ after $1 \mathrm{~h} \mathrm{[19].} \mathrm{However,}$ Astete et al. synthesized Span80-stabilized TP-containing PLGA50-based nanosized particles in the range of 150-200 nm and the effect of salt concentration on the size and morphology of the NPs has been interpreted, but data for the drug loading and release were not presented [21]. Murugeshu and coworkers also synthesized chitosan/PLGA50-based TP-containing NPs with $8 \%, 16 \%$ and $24 \%$ initial loading, but the EE\% was only $45-50 \%$ and the release studies were carried out in gastrointestinal conditions ( $\mathrm{pH} \sim 1.50$ ) [22]. Simon et al. successfully encapsulated the TP into PLGA50 using PVA, but only $2.5 \mathrm{mg}$ drug/100 $\mathrm{mg}$ NPs can be obtained [23].

In our previous work, the TP as well as the water-soluble derivative of TP (D, $\alpha$-Tocopherol polyethylene glycol 1000 succinate (TPGS)) and the non-steroidal anti-inflammatory ketoprofen (KP) have been successfully encapsulated into PLA and PLGA75 (lactide:glycolide ratio 75:25) and PLGA65 (lactide:glycolide ratio 65:35) nanocarriers [13]. Instead of the commonly used and above mentioned PLGA50, the PLGA65 and PLGA75 derivatives have been firstly used as carriers for the encapsulation of $\mathrm{TP}$, and the hydrophilicity properties of the carriers and the model drugs on the EE\% have been studied in detail. The release measurements of nanocomposites including hydrophobic drugs are very difficult to carry out. In order to facilitate the above-mentioned studies, stabilizing agents such as surfactants have been widely used [5,19]. Non-ionic poloxamer Pluronic F127 was applied previously, which stabilized the drug-containing polymeric NPs by increasing the biocompatibility. The optimal ratios of the carrier, the drug and the stabilizing agent have a dominant effect on the structure and the $\mathrm{EE} \%$, as well as the controlled drug release process of the nanosized drug delivery systems, which were not studied previously.

In the present work, the results of the TP-containing nanocomposites, using PLA, PLGA65 and PLGA75 carriers, have been completed and the determinative role of the concentration of the polymer, the TP and the PLUR stabilizing agent on the structure of the drug-containing nanocomposites has been investigated. Moreover, the drug release studies of the prepared TP-containing PLA, PLGA65 and PLGA75 core-shell NPs have also been interpreted.

\section{Materials and Methods}

\subsection{Materials}

Polylactide (PLA, $\mathrm{Mw}=72,200 \pm 15,000 \mathrm{Da}$ ) and two poly(lactide-co-glycolide) (PLGA) derivatives with a lactide to glycolide ratio at 75:25 (PLGA75, $\mathrm{Mw}=69,900 \pm 4000 \mathrm{Da}$ ) and at 65:35 (PLGA65, $\mathrm{Mw}=93,000 \pm 1000 \mathrm{Da}$ ) were synthetized according to the previously published procedure [13]. Pluronic F127 (PLUR), $( \pm)-\alpha$-tocopherol (TP) and sodium phosphate monobasic monohydrate $\left(\mathrm{NaH}_{2} \mathrm{PO}_{4} \cdot \mathrm{H}_{2} \mathrm{O}, \geq 99 \%\right)$ were obtained from Sigma Aldrich (Budapest, Hungary). Sodium phosphate dibasic anhydrous $\left(\mathrm{Na}_{2} \mathrm{HPO}_{4}, \geq 99 \%\right)$ and sodium chloride $(\mathrm{NaCl}, \geq 99 \%)$ were purchased from Molar Chemicals (Halásztelek, Hungary). All other reagents and solvents were of analytical grade and used without further purification. The deionized water was obtained by Millipore purification apparatus $\left(18.2 \mathrm{M} \Omega \mathrm{cm}\right.$ at $\left.25^{\circ} \mathrm{C}\right)$. 


\subsection{Preparation of TP-Loaded PLA/PLGA NPS}

The TP-loaded PLA/PLGA NPs were prepared by nanoprecipitation method (Figure 1). The detailed experimental conditions were presented previously [13]. Briefly, the PLA/PLGA and TP with increasing concentrations (see Table 1) were dissolved in $1.5 \mathrm{~mL}$ of acetone, which was dropped slowly $(10 \mu \mathrm{L} / 5 \mathrm{~s})$ into the aqueous solution of the PLUR stabilizer $(15 \mathrm{~mL})$ under room temperature using magnetic stirring with $1000 \mathrm{rpm}$. In the interest of the evaporation of acetone, the prepared samples were further stirred (350 rpm) for two days. The dispersion was centrifugated with $40 \mathrm{~mL}$ MQ water at $12,000 \mathrm{rpm}\left(t=15 \mathrm{~min}, T=25^{\circ} \mathrm{C}\right)$. After the supernatant was removed, the NPs were redispersed in MQ water and the washing methods were repeated two times. The obtained NPs samples were freeze-dried by liquid nitrogen and lyophilized (by Christ Alpha 1-2 LDplus apparatus).

Table 1. The concentration of the components, the average particle diameter, the polydispersity index (PI), the encapsulation efficiency (EE\%) and the drug loading (DL\%) of the TP-loaded PLA NPs.

\begin{tabular}{|c|c|c|c|c|c|c|c|}
\hline \multirow[b]{2}{*}{ Sample } & \multicolumn{2}{|c|}{ Acetone Phase } & \multicolumn{2}{|l|}{ Aqueous Phase } & \multirow[b]{2}{*}{$\mathrm{PI} \pm \mathrm{SD}$} & \multirow[b]{2}{*}{$\mathrm{EE} \%$} & \multirow[b]{2}{*}{ DL\% } \\
\hline & $\begin{array}{c}c_{\text {PLA }} \\
\left(\mathrm{mg} \cdot \mathrm{mL}^{-1}\right)\end{array}$ & $\begin{array}{c}\mathrm{c}_{\mathrm{TP}} \\
\left(\mathrm{mg} \cdot \mathrm{mL}^{-1}\right)\end{array}$ & $\mathrm{C}_{\text {PLUR }}\left(\mathrm{mg} \cdot \mathrm{mL}^{-1}\right)$ & $\begin{array}{c}\mathrm{d}_{\mathrm{DLS}} \pm \mathrm{SD}^{1} \\
(\mathrm{~nm})\end{array}$ & & & \\
\hline \multirow{4}{*}{$\begin{array}{l}\text { PLA } \\
\text { concentration } \\
\text { dependence }\end{array}$} & 1.25 & 2.5 & 0.1 & $120 \pm 33$ & $0.120 \pm 0.043$ & - & - \\
\hline & 2.5 & 2.5 & 0.1 & $156+28$ & $0.039 \pm 0.012$ & - & - \\
\hline & 5.0 & 2.5 & 0.1 & $179 \pm 35$ & $0.082 \pm 0.049$ & - & - \\
\hline & 10.0 & 2.5 & 0.1 & $201 \pm 38$ & $0.095 \pm 0.026$ & 69.11 & 14.73 \\
\hline \multirow{5}{*}{\begin{tabular}{l}
\multicolumn{1}{c}{ TP } \\
concentration \\
dependence
\end{tabular}} & 10.0 & 0 & 0.1 & $188 \pm 37$ & $0.092 \pm 0.059$ & - & - \\
\hline & 10.0 & 0.5 & 0.1 & $189 \pm 34$ & $0.048 \pm 0.028$ & 91.28 & 4.36 \\
\hline & 10.0 & 1.0 & 0.1 & $192 \pm 30$ & $0.062 \pm 0.032$ & 75.61 & 7.02 \\
\hline & 10.0 & 2.5 & 0.1 & $201 \pm 38$ & $0.095 \pm 0.026$ & 69.11 & 14.73 \\
\hline & 10.0 & 5.0 & 0.1 & $252 \pm 53$ & $0.073 \pm 0.033$ & 66.15 & 24.85 \\
\hline \multirow{5}{*}{$\begin{array}{l}\text { PLUR } \\
\text { concentration } \\
\text { dependence }\end{array}$} & 10.0 & 2.5 & 0 & $179 \pm 40$ & $0.315 \pm 0.040$ & 72.19 & 15.29 \\
\hline & 10.0 & 2.5 & 0.05 & $178 \pm 21$ & $0.304 \pm 0.095$ & 98.34 & 19.73 \\
\hline & 10.0 & 2.5 & 0.1 & $201 \pm 38$ & $0.095 \pm 0.026$ & 69.11 & 14.73 \\
\hline & 10.0 & 2.5 & 0.5 & $206 \pm 36$ & $0.089 \pm 0.065$ & 57.94 & 12.65 \\
\hline & 10.0 & 2.5 & 1.0 & $212 \pm 36$ & $0.066 \pm 0.029$ & 40.75 & 9.24 \\
\hline
\end{tabular}

${ }^{1}$ The experimental error of the peak maximum is below $2.5 \%$.

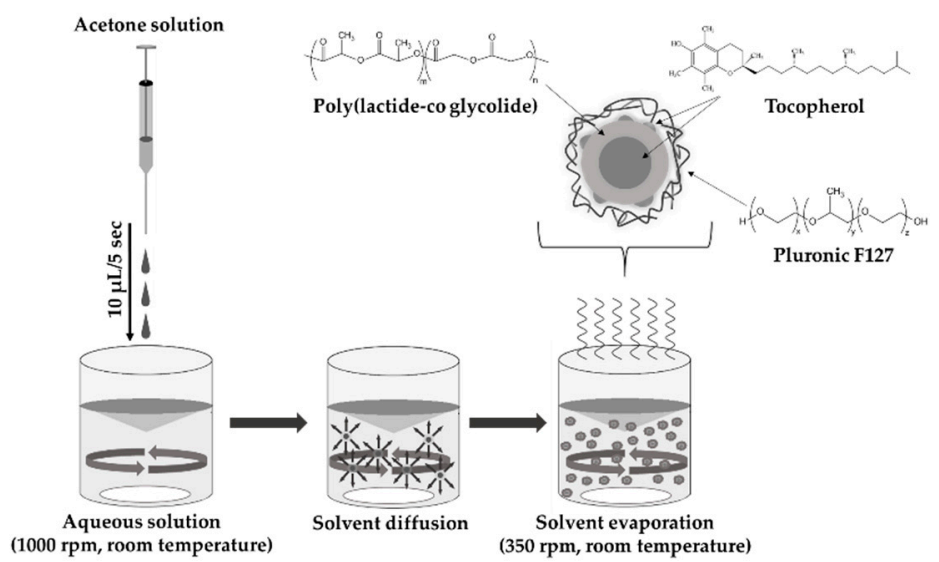

Figure 1. Schematic representation of the preparation of TP-loaded PLGA NPs stabilized by PLUR using nanoprecipitation technique.

\subsection{Characterization Methods}

The particle size was determined by dynamic light scattering (DLS) with Horiba Sz-100 (HORIBA Jobin Yvon, Longjumeau, France) equipped with a diode pumped frequency doubled ( $532 \mathrm{~nm}, 10 \mathrm{~mW})$ laser. The measurements were carried out at $25 \pm 0.1^{\circ} \mathrm{C}$ with $90^{\circ}$ of detection angle in every case. 
The transmission electron microscopy (TEM) images were obtained by Jeol JEM-1400plus equipment (JEOL Ltd., Tokyo, Japan) at $120 \mathrm{keV}$ accelerating voltage. The Fourier transform infrared (FT-IR) spectra of the PLA/PLGA-TP NPs were registered by a Jasco FT/IR-4700 with ATR PRO ONE Single-reflection accessory (ABL\&JASCO, Budapest, Hungary). The experiments were performed at room temperature from $600 \mathrm{~cm}^{-1}$ to $3600 \mathrm{~cm}^{-1}$. The resolution of the spectra was $2 \mathrm{~cm}^{-1}$, which was determined by 128 interferograms.

The particles were dissolved in 1,4-dioxane to determine the EE\% and DL\% of the composites. The absorbance spectra of the prepared solutions were measured by a Shimadzu UV-1800 UV-Vis double beam spectrophotometer. The spectra were registered in the range of 200-500 $\mathrm{nm} \mathrm{using} 1 \mathrm{~cm}$ quartz cuvette at room temperature. The characteristic absorbance band of the TP appeared at $294 \mathrm{~nm}$. The concentration of the encapsulated drug was determined from the calibration curve (Figure S1). The data of the $\mathrm{EE} \%$ in $w / w \%$ were calculated by the total drug mass used in the synthesis of the NPs (Equation (1)), while DL\% was calculated by the mass of the NPs (Equation (2)).

$$
\begin{aligned}
& E E \%=\frac{\text { encapsulated mass of drug }}{\text { total mass of drug in synthesis }} \times 100 \\
& D L \%=\frac{\text { encapsulated mass of drug }}{\text { total mass of the nanoparticles }} \times 100
\end{aligned}
$$

\subsection{Determination of the Solubility Properties of TP Drug}

In order to determine the solubility of $\mathrm{TP}, 100 \mu \mathrm{L}$ of acetone solutions of $\mathrm{TP}\left(5 \mathrm{mg} \cdot \mathrm{mL}^{-1}\right)$ was added dropwise to $10 \mathrm{~mL}$ of PLUR solutions $\left(0.1-1.2 \mathrm{mg} \cdot \mathrm{mL}^{-1}\right)$, and the turbidity was followed with a Precision Bench Turbidity Meter LP2000 (Hanna Ins. Service Kft., Szeged, Hungary). The experiments were performed in a pure aqueous medium and in a phosphate (PBS) buffer $(\mathrm{pH}=7.4,0.9 \% \mathrm{NaCl})$ solution at $25^{\circ} \mathrm{C}$ and $37^{\circ} \mathrm{C}$.

\subsection{Critical Micelle Concentration (cmc) Studies}

The critical micelle concentration ( $\mathrm{cmc}$ ) of the applied PLUR was determined by inverse titration method in Krüss K100MK2 type surface tension equipment. The computer-controlled apparatus was supplied with a thermostat and an automatic burette. The Wilhelmy-plate method was applied. A volume of $50 \mathrm{~mL}$ of a $1.6 \mathrm{mM}$ surfactant solution was titrated with MQ water or PBS in an aliquot of $10 \mathrm{~mL}$ in 40 steps. Each experimental point was the average of at least 5 measurements.

\subsection{In Vitro Release Study}

The in vitro studies of the different TP-loaded PLA/PLGA NPs were carried out by a UV-Vis spectrophotometer (500-200 nm). The release experiments were performed at $37^{\circ} \mathrm{C}$ and a PBS buffer $\left(\mathrm{pH}=7.4, \mathrm{NaCl} 0.9 \%\right.$ ) containing $1 \mathrm{mg} \cdot \mathrm{mL}^{-1}$ of PLUR was used, which facilitated the easier feasibility of the release studies [5]. The TP-loaded samples were placed into the cellulose membrane (Sigma Aldrich) with $5 \mathrm{~mL}$ of PLUR/PBS medium inserted into $35 \mathrm{~mL}$ of a dissolution phase. During the measurements, $3 \mathrm{~mL}$ of the release media were taken at specified intervals to measure the released concentration of TP at $268 \mathrm{~nm}$.

The release curves of the TP can be fitted by different kinetic models, such as the first order, Korsmeyer-Peppas, Peppas-Sahlin and Weibull models [24-27]. The measured points were fitted with a nonlinear regression by the QtiPlot 0.9.8.9 svn 2288 program. During the calculation session, the program finds the best fitting function for the measured points. The results consist of the fitted parameters, their standard deviation and the goodness of fitting (root mean squared error).

Depending of the release chemical condition (such as temperature, buffer solution, ionic strength, etc.), the shape of the polymers and the solubility of the drugs, the dissolution curves can be described with different kinetic models. For our calculation, the following kinetic models were used. 
First order equation is a frequently used kinetic model. This formula is well applicable for drugs where the dissolution is continuously changing over time and depends only on the concentration.

$$
c_{t}=c e^{-k t}
$$

where $c_{t}$ is the concentration of the solid drug in the matrix of the carried system at $t$ time, $c_{0}$ is the initial concentration of the drug and $k$ is the first order release constant.

The Korsmeyer-Peppas kinetic formula is a semi-empirical power law equation where the shape of the polymer matrix (such as film, cylinder or sphere) can be taken into account in the release curve.

$$
\frac{c_{t}}{c_{0}}=k_{m} t^{n}
$$

where $c_{t}$ is the concentration of the dissolved drug at $t$ time, $c_{0}$ is the initial concentration of drug, $k_{m}$ is the kinetic constant and $\mathrm{n}$ is the diffusion dissolution index (for sphere shaped particles $n=0.42$ for the diffusion-controlled mechanism, $n=1$ for the Case II relaxation controlled mechanism and $0.42 \leq n \leq 1$ for both of them).

The Weibull equation is a general empirical formula which can be used for all release profiles.

$$
c_{t}=1-\exp \left(\frac{-\left(t-T_{i}\right)^{b}}{a}\right)
$$

where $c_{t}$ is the concentration of the released component in $t$ time, $T_{i}$ is the lag time between the initial of measurement and the release of drug (in most cases $T_{i}=0$ ), $a$ is the time scale of the process and $b$ is the shape parameter (shape of the release curve is exponential if $b=1$, parabola if $b<1$ or sigmoid if $b>1$ ).

The kinetic formula reported by Peppas and Sahlin specifies the diffusion and the relaxation contribution in the drug dissolution process.

$$
\frac{c_{t}}{c_{0}}=k_{1} t^{m}+k_{2} t^{2 m}
$$

where $c_{t}$ is the concentration of the dissolved drug in the $t$ time, $c_{0}$ is the initial concentration of the drug and $k_{1}, k_{2}$ and $m$ are constants: $k_{1}$ is the Fick diffusion contribution, $k_{2}$ is the Case II relaxation contribution and $m$ is the diffusion exponent (sphere shaped: $m=0.43$, Fick diffusion mechanism; $m=0.85$, Case II relaxation transport mechanism; $0.43 \leq m \leq 0.85$, anomalous transport mechanism).

\section{Results}

\subsection{Effect of the Component Concentrations on the Core-Shell Structure}

In order to determine the role of the component quantities of the nanocomposites on the size and the structure, as well as on the $\mathrm{EE} \%$ the concentration, only one building block (polymer carrier, drug or stabilizing agent) has been modified during the synthesis while the other parameters have been kept constant. The average particle diameters of the NPs were measured by DLS, and the results are summarized in Table 1 . In case of PLA concentration dependence, regardless of the amount of the TP $\left(\mathrm{c}=2.5 \mathrm{mg} \cdot \mathrm{mL}^{-1}\right)$, the diameter of the NPs permanently increases from $120 \mathrm{~nm}$ $\left(c_{P L A}=1.25 \mathrm{mg} \cdot \mathrm{mL}^{-1}\right.$ in aceton phase $)$ to ca. $200 \mathrm{~nm}\left(\mathrm{CPLA}_{10}=10 \mathrm{mg} \cdot \mathrm{mL}^{-1}\right.$ in the acetone phase $)$. The morphology and the structure of the NPs have been investigated by TEM images as well (Figure 2). The images clearly represent that the structure of the TP/PLUR NPs in the absence of a polymer shows less amorphous structures and TP crystal-like objects are observed. Moreover, we established that an increase in the polymer concentration results in the formation of a well-defined core-shell structure at $c_{\text {PLA }}=10.0 \mathrm{mg} \cdot \mathrm{mL}^{-1}$. At lower polymer concentrations, this structure is not formed, and because of the low polymer concentration, the purification (centrifugation) of the NPs is impracticable; thus, the determination of the EE\% was not possible. For TP that is concentration-dependent, the 
diameters show a slightly increasing tendency to $2.5 \mathrm{mg} \cdot \mathrm{mL}^{-1}$, but for a $5 \mathrm{mg} \cdot \mathrm{mL}^{-1}$ amount of TP, a higher size is obtained $\left(\mathrm{d}_{\text {DLS }}=252 \mathrm{~nm}\right)$ (Table 1$)$. The TEM images also confirm this observation (Figure 2). The well-defined core-shell structure is formed at $2.5 \mathrm{mg} \cdot \mathrm{mL}^{-1}$ of TP quantity. With a further increase in the TP amount, the core, including the drug, shows a rather crystallized structure instead of the previously confirmed amorphous form. The EE\% and the drug loading were determined for all composites. We obtained that the value of the EE\% decreased from $91.28 \%\left(\mathrm{c}_{\mathrm{TP}}=0.5 \mathrm{mg} \cdot \mathrm{mL}^{-1}\right)$ to $66.15 \%\left(\mathrm{c}_{\mathrm{TP}}=5 \mathrm{mg} \cdot \mathrm{mL}^{-1}\right)$, while the $\mathrm{DL} \%$ increased from $4.36 \%\left(\mathrm{c}_{\mathrm{TP}}=0.5 \mathrm{mg} \cdot \mathrm{mL}^{-1}\right)$ to $24.85 \%$ $\left(c_{\mathrm{TP}}=5 \mathrm{mg} \cdot \mathrm{mL}^{-1}\right)$. Considering the expected size of the NPs for optimal nanosized drug delivery systems (ca. $200 \mathrm{~nm}$ ) as well as the crystallization of the core, the $2.5 \mathrm{mg} \cdot \mathrm{mL}^{-1}$ amount of TP will be used for further studies at $10.0 \mathrm{mg} \cdot \mathrm{mL}^{-1}$ of PLA polymer concentration. Besides optimizing the amount of carrier and active drug, the ratio of the stabilizing PLUR surfactant was also studied. It was clearly confirmed that in the absence of PLUR, the TP molecules were not capsulated into the polymer core, only the binding of the TP drugs onto the surface of the polymer shell is observed (Figure 2). Furthermore, it was established that the smallest particle diameter $(\mathrm{d}=178 \mathrm{~nm})$, as well as the highest DL\% (ca. $20 \%$ ), is obtained at $0.05 \mathrm{mg} \cdot \mathrm{mL}^{-1}$ of PLUR concentration. Increase in the PLUR amount resulted in a higher particle size $(212 \mathrm{~nm})$ as well as a lower DL\% values (9\%). Most probably, the increase in the PLUR concentration facilitated the solubility of the hydrophobic TP, thus hindering the encapsulation process. In order to confirm the above-mentioned phenomena, turbidity measurements were carried out (Figure S2). According to the TEM images (Figure 2) and the turbidity studies (Figure S2), we can conclude that a low quantity $\left(0.1 \mathrm{mg} \cdot \mathrm{mL}^{-1}\right)$ of PLUR surfactant is advantageous for the formation of PLA-based core-shell NPs, but the presence of a higher amount of PLUR $\left(>0.1 \mathrm{mg} \cdot \mathrm{mL}^{-1}\right)$ results in the decrease of the EE\%. Moreover, the presence of a higher amount of stabilizer $\left(\geq 1.0 \mathrm{mg} \cdot \mathrm{mL}^{-1}\right)$ causes aggregation (Figure 2 ).

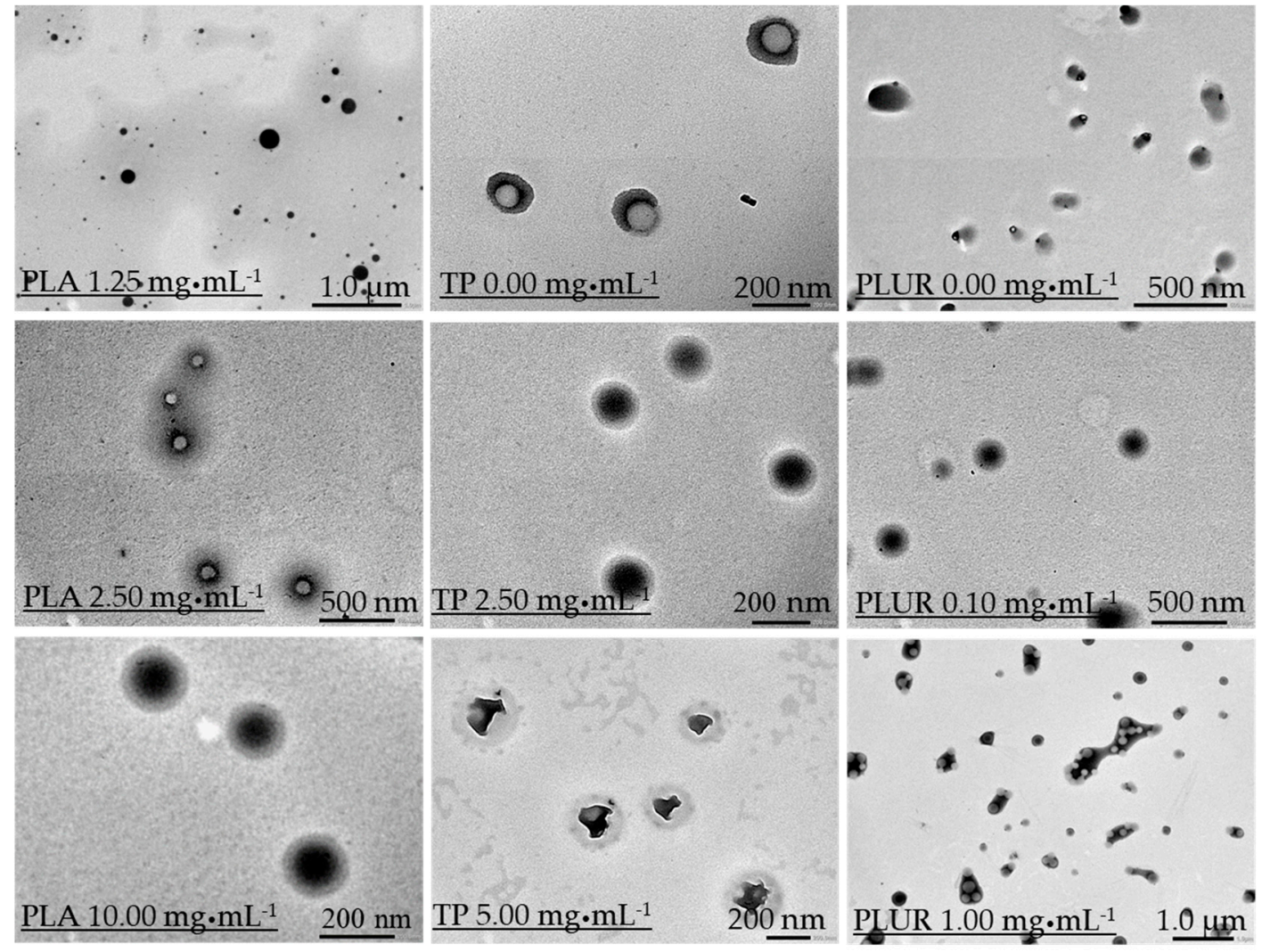

Figure 2. Representative TEM images of the TP-containing PLA NPs using different component concentrations (PLA: $1.25-10.0 \mathrm{mg} \cdot \mathrm{mL}^{-1}$; TP: 0-5.0 $\mathrm{mg} \cdot \mathrm{mL}^{-1}$ and PLUR: $0-1.0 \mathrm{mg} \cdot \mathrm{mL}^{-1}$ ). 
Besides the determination of the optimal ratio of the composite building blocks, the TP was encapsulated in PLGA75 and PLGA65 copolymers that have increasing hydrophilicity. During the NPs synthesis, the previously optimized concentrations of the polymer carrier $\left(10.0 \mathrm{mg} \cdot \mathrm{mL}^{-1}\right)$, the PLUR $\left(0.1 \mathrm{mg} \cdot \mathrm{mL}^{-1}\right)$ and the TP $\left(2.5 \mathrm{mg} \cdot \mathrm{mL}^{-1}\right)$ were used. Based on DLS studies, we established that the particle size increases from $203 \mathrm{~nm}$ to $226 \mathrm{~nm}$ with a decrease of the lactide part in the polymer (Figure 3A). Using the optimized component quantities, the core-shell structure was confirmed for PLGA75 and PLGA65-based TP-containing NPs (Figure 3B). The EE\% and DL\% has been determined for the PLGA75 and PLGA65-based system as well, and we observed that the replacement of the PLA carrier to PLGA75 and PLGA65 polymers resulted in the increase in the EE\% to 75.72\% and 87.69\%, respectively. In addition, the drug loading also increased from 14.73\% (PLA) to 15.92\% (PLGA75) and to $17.98 \%$ (PLGA65) with decreasing lactide content. The higher EE\% and DL\% can be explained by the fact that the precipitation of the more hydrophilic PLGA carriers is slower than that for PLA and $\mathrm{TP}$, which helps the formation of the well-defined core-shell structure [13].

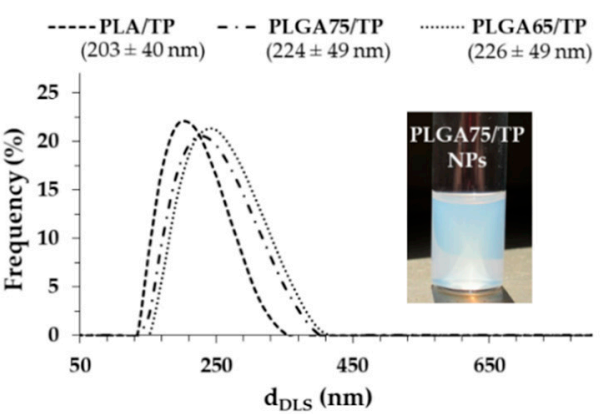

(a)

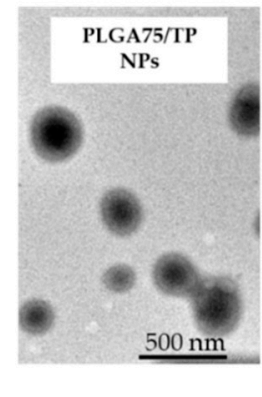

(b)

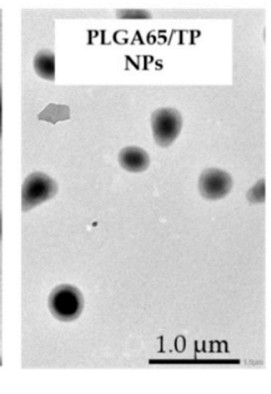

(c)

Figure 3. The particle size distribution of the TP-loaded PLA and PLGA NPs (a), and representative TEM images of the PLGA75-(b) and PLGA65-(c) based composites.

\subsection{Structural Characterization of the TP-Loaded PLA and PLGA Core-Shell NPS}

To determine the interaction between the PLA and TP, the composites have been examined by infrared spectroscopy measurements. Figure 4 displays the spectra of the PLA-based NPs in the absence (Figure 4A) and in the presence of TP at different concentrations (Figure 4B,C). The TP-sensitive bands appear in the range of $3050-2800 \mathrm{~cm}^{-1}$ and $1150-1000 \mathrm{~cm}^{-1}$. It is obvious that the intensity of all the determinative bands systematically increase by increasing TP content. At 2994, 2944 and $2968 \mathrm{~cm}^{-1}$, the asymmetric and symmetric $\mathrm{CH}$ stretching vibrations of the $-\mathrm{CH}_{2}$ and $-\mathrm{CH}_{3}$ groups of the drug appear. Due to the increasing TP concentration, these bands become more intense, indicating the presence of TP molecules in the polymer NPs. The carbonyl group of the PLA appears at $1750 \mathrm{~cm}^{-1}[28,29]$. The TP does not contain a $\mathrm{C}=\mathrm{O}$ group, thus this band could originate only from the polymer. In the fingerprint region $\left(v \leq 1500 \mathrm{~cm}^{-1}\right)$, the deformation and bending vibration of the $-\mathrm{CH}_{3}$ and $-\mathrm{CH}_{2}$ groups appear at 1453,1381 and $1267 \mathrm{~cm}^{-1}$, while the band at $1181 \mathrm{~cm}^{-1}$ attributes to the stretching mode of the $\mathrm{C}-\mathrm{O}-\mathrm{C}$ (ester). At around $1086 \mathrm{~cm}^{-1}$, further bands of the $\mathrm{C}-\mathrm{O}-\mathrm{C}$ stretching vibration can be observed, which have shoulders (symmetric and asymmetric stretching vibrations). Because of the Ar-O-C group in the TP, the intensity of this C-O-C symmetric stretching vibration at around $1050 \mathrm{~cm}^{-1}$ is increased. The band at $865 \mathrm{~cm}^{-1}$ and $751 \mathrm{~cm}^{-1}$ is characteristic of the polymer carrier, and no shift is observed. The IR measurements performed for PLGA75 and PLGA65 resulted in similar spectra. A strong irreversible interaction between the PLA (or PLGA75, PLGA65) and the TP cannot be discovered (Figures S3 and S4), which facilitates the spontaneous release of the TP active drug from the polymer NPs, but the presence of the TP in the different composites were definitely confirmed by IR. 
<smiles>C=C(C)C(=O)C(C)OC1CCC1(C)C(C)C</smiles>

Polylactide
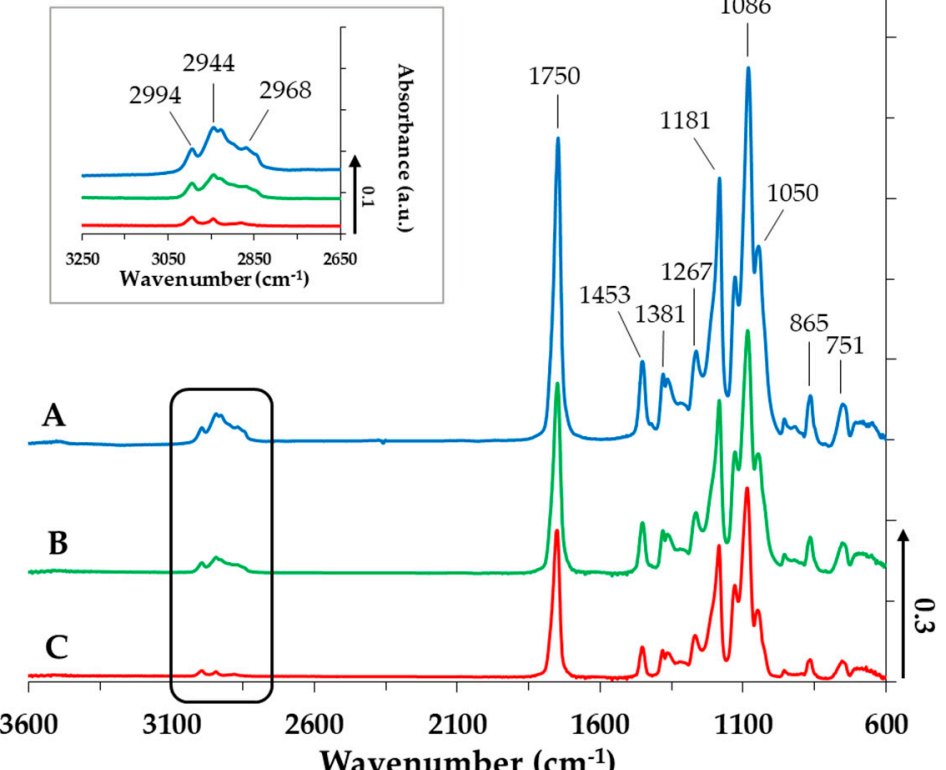

( \pm - $\alpha$-Tocopherol

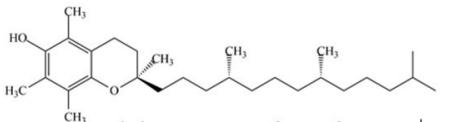

1750

${ }_{1381}^{1267}$

i

Figure 4. IR spectra of the TP-loaded PLA NPs (A: $\mathrm{c}_{\mathrm{TP}}=0 \mathrm{mg} \cdot \mathrm{mL}^{-1} ; \mathrm{B}: \mathrm{c}_{\mathrm{TP}}=2.5 \mathrm{mg} \cdot \mathrm{mL}^{-1}$; $\mathrm{C}: \mathrm{c}_{\mathrm{TP}}=5 \mathrm{mg} \cdot \mathrm{mL}^{-1}, \mathrm{c}_{\mathrm{PLA}}=10 \mathrm{mg} \cdot \mathrm{mL}^{-1}$ and $\left.\mathrm{c}_{\mathrm{PLUR}}=0.1 \mathrm{mg} \cdot \mathrm{mL}^{-1}\right)$.

Turbidimetric measurements were performed to investigate the interaction between the TP and the PLUR stabilizing agent in a pure aqueous solution and in $\mathrm{PBS}$ at $25^{\circ} \mathrm{C}$ and $37^{\circ} \mathrm{C}(\mathrm{pH}=7.4,0.9 \% \mathrm{NaCl})$; the results are presented in Figure 5. In MQ water (Figure 5A), the turbidity of TP is systematically decreased till ca. $0.9 \mathrm{mg} \cdot \mathrm{mL}^{-1}$ of PLUR concentration. Over time, more and more TP can dissolve in this medium. In contrast, in the PBS solution at $25^{\circ} \mathrm{C}$ and at $37{ }^{\circ} \mathrm{C}$, the titration curves exhibit steeper decreasing intensity, which may be due to the reduced critical micellization concentration $(\mathrm{cmc})$ of PLUR in the presence of salt. In the case of the PBS solution, the turbidity remains constant from $0.7 \mathrm{mg} \cdot \mathrm{mL}^{-1}$ at $25^{\circ} \mathrm{C}$, while an increase in the temperature to $37^{\circ} \mathrm{C} 0.6 \mathrm{mg} \cdot \mathrm{mL}^{-1}$ value is observed. It is important to mention that the solubility of the TP scarcely depends on time at $37^{\circ} \mathrm{C}$, which allows the possible use of the PLUR stabilizing agent for in vitro drug release measurements.

It is well known that the surfactant affects the solubility of the TP drug in the absence of a polymer carrier. Namely, above $\mathrm{cmc}$, due to the micellization ability of the PLUR, the solubilization of the drug dominates forming TP-loaded individual micelles, while below $\mathrm{cmc}$, only the solubility increases. Accordingly, the cmc of the PLUR was measured by surface tension measurements (Figure 6). In the literature, very different values can be found; the obtained range of $\mathrm{cmc}$ is $2-7 \mathrm{mg} \cdot \mathrm{mL}^{-1}[30,31]$. Similar values were measured, but we determined that at $25^{\circ} \mathrm{C}$, the obtained $\mathrm{cmc}$ is decreased from $4.92 \mathrm{mg} \cdot \mathrm{mL}^{-1}$ to $1.99 \mathrm{mg} \cdot \mathrm{mL}^{-1}$ in the presence of the phosphate buffer. If the temperature rises from $25^{\circ} \mathrm{C}$ to $37^{\circ} \mathrm{C}$, these values are further decreased. We can conclude that the concentration of the PLUR in the composites is significantly lower than the $\mathrm{cmc}\left(4.92 \mathrm{mg} \cdot \mathrm{mL}^{-1}\right)$ value, which excludes the presence of TP-loaded individual micelles. 


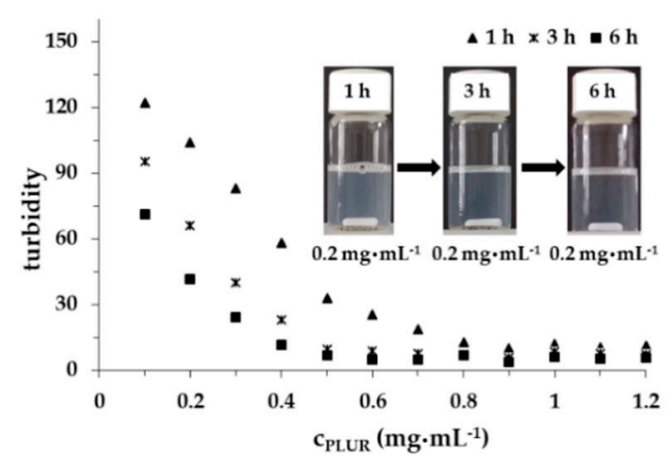

(a)

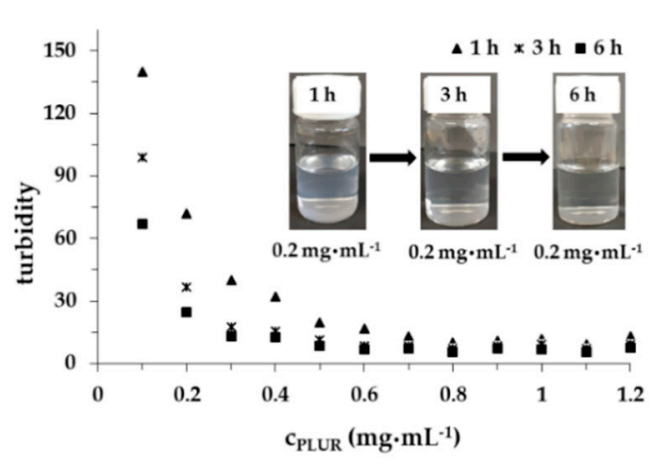

(b)

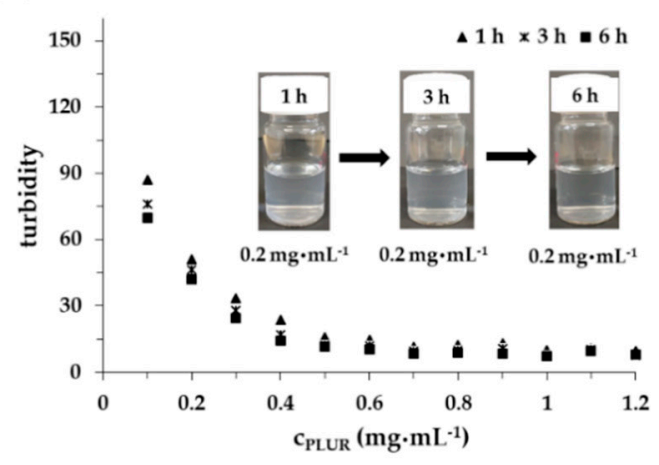

(c)

Figure 5. The turbidity of the TP in the PLUR solution at $25^{\circ} \mathrm{C}$ in an aqueous medium (a), in a PBS buffer at $25^{\circ} \mathrm{C}(\mathbf{b})$ and at $37^{\circ} \mathrm{C}(\mathbf{c})(\mathrm{pH}=7.4,0.9 w / w \% \mathrm{NaCl})\left(\mathrm{c}_{\mathrm{TP}}=0.05 \mathrm{mg} \cdot \mathrm{mL}^{-1}\right)$.

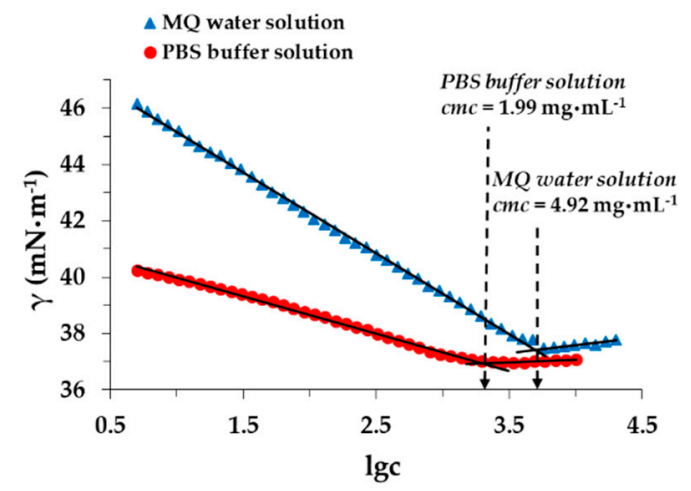

Figure 6. Determination of PLUR $\mathrm{cmc}$ at $25^{\circ} \mathrm{C}$ in MQ water and in a PBS solution.

\subsection{In Vitro Drug Release Experiments}

The determination of the exact TP amount released from the different composites was carried out by the UV-Vis spectrophotometric method. The spectra of the TP and the calibration curve are presented in Figure 7. The absorption bands of the TP appear in the UV range. 


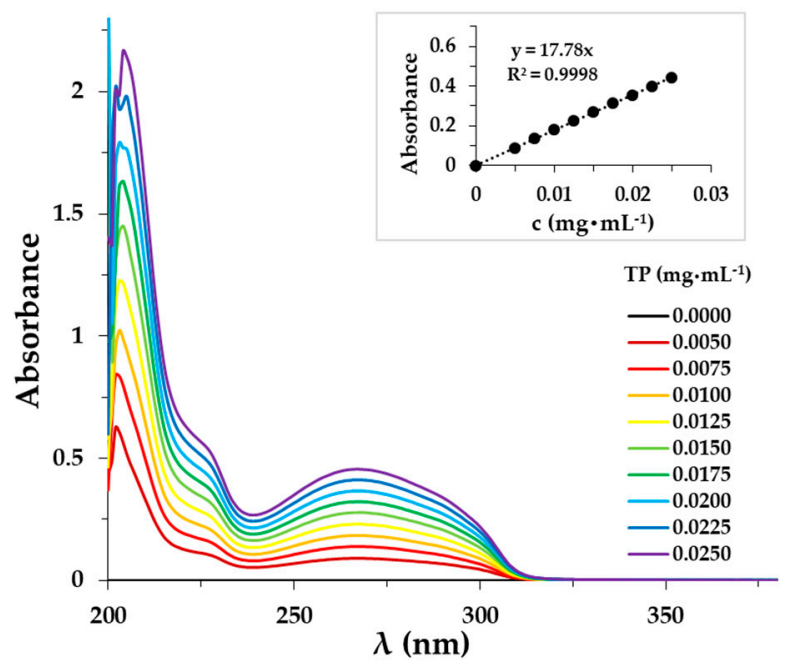

Figure 7. UV spectra of the TP in the PBS solution ( $\left.\mathrm{C}_{\mathrm{PLUR}}=1.0 \mathrm{mg} \cdot \mathrm{mL}^{-1}, 0.9 w / w \% \mathrm{NaCl}\right)$.

After the characterization of the TP-loaded PLA and PLGA NPs, the mechanism of the drug release was investigated. The drug dissolution profiles and the fitting of these curves by different kinetic models are demonstrated in Figure 8 (Figure S5). The suitability of several models like Korsmeyer-Peppas, Peppas-Sahlin, the first-order and the Weibull models were investigated. The release curves clearly show that a high amount of TP is retained in the polymers after $7 \mathrm{~h}$. It was also observed that in the first half an hour, the dissolution of the drug occurs relatively quickly, but after that, measurable slow dissolution is observed. Moreover, we found that the active substance is released slowly with a decrease of the lactide part (PLA, 35.0\%, PLGA75, 28.3\%, PLGA65, 19.8\%) in $7 \mathrm{~h}$. The slowest dissolution occurred in the carrier-free TP (15\%). Because of the higher hydrophobicity, a higher amount of the non-encapsulated drug can be attached to the surface of the particles, which confirms the above-mentioned dissolution order [13]. Thanks to the application of the nanosized drug carrier systems (polymer NPs), the TP molecules can bind to the enhanced specific surface area of the NPs, which facilitates the dissolution of more TP, in contrast to the bulk TP.

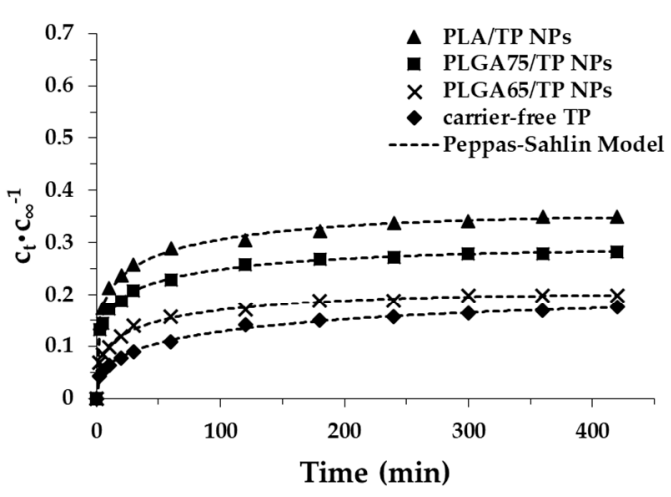

(a)

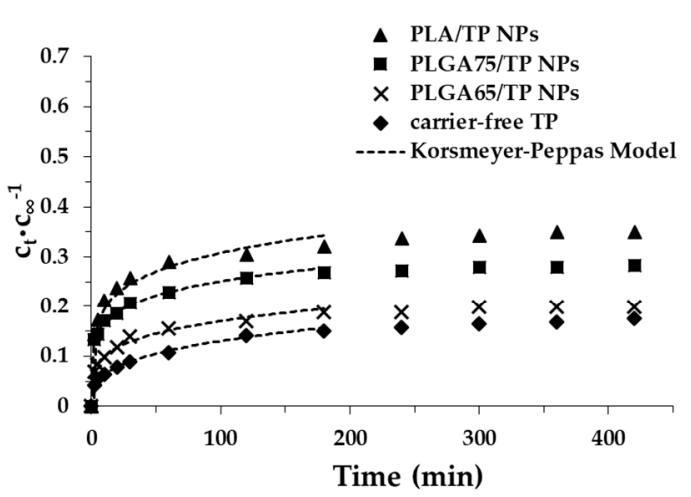

(b)

Figure 8. Release profiles and different kinetic models-predicted (Peppas-Sahlin model (a), Korsmeyer-Peppas model (b)) for the release curves of TP from PLA and PLGA NPs in the PBS buffer $(\mathrm{pH}=7.4,0.9 w / w \% \mathrm{NaCl})$.

Taking into account the coefficient of the determination $\left(R^{2}\right)$, the Peppas-Sahlin model was the best kinetic formula for our systems (Table 2). The values of the Case II relaxation contribution $\left(k_{2}\right)$ were negative in all cases; therefore, this model does not provide complete information about the dissolution of the TP, but the low diffusion exponent $(m)$ is referred to for the Fickian release. 
Table 2. Determined parameters of the TP release by fitting several kinetic equations.

\begin{tabular}{ccccc}
\hline Peppas-Sahlin Formulation & $\boldsymbol{k}_{\mathbf{1}}\left(\mathbf{m i n}^{-\mathbf{m}}\right)$ & $\boldsymbol{k}_{\mathbf{2}}\left(\mathbf{m i n}^{-\mathbf{2 m}}\right)$ & $\boldsymbol{m}$ & $\boldsymbol{R}^{\mathbf{2}}$ \\
\hline PLA/TP NPs & 0.1371 & -0.01346 & 0.260 & 0.9974 \\
PLGA75/TP NPs & 0.1165 & -0.01189 & 0.248 & 0.9986 \\
PLGA65/TP NPs & 0.0572 & -0.00412 & 0.317 & 0.9974 \\
TP & 0.0304 & -0.00124 & 0.366 & 0.9978 \\
\hline Korsmeyer-Peppas Formulation & $\boldsymbol{k}_{\boldsymbol{m}}\left(\mathbf{m i n}^{-\boldsymbol{n}}\right)$ & $\boldsymbol{n}$ & $\boldsymbol{R}^{\mathbf{2}}$ \\
\hline PLA/TP NPs & 0.1339 & 0.182 & 0.9898 \\
PLGA75/TP NPs & 0.1120 & 0.175 & 0.9982 \\
PLGA65/TP NPs & 0.0592 & 0.223 & 0.9904 \\
TP & 0.0310 & 0.311 & 0.9977 \\
\hline Weibull Formulation & $\boldsymbol{a}$ & $\boldsymbol{b}$ & \multicolumn{2}{c}{$\boldsymbol{R}^{\mathbf{2}}$} \\
\hline PLA/TP NPs & 6.52 & 0.178 & 0.9896 \\
PLGA75/TP NPs & 7.85 & 0.166 & \multicolumn{2}{c}{0.9819} \\
PLGA65/TP NPs & 15.45 & 0.220 & \multicolumn{2}{c}{0.9945} \\
TP & 28.19 & 0.285 & $\boldsymbol{R}^{\mathbf{2}}$ & \\
\hline First Order Formulation & $\boldsymbol{k}\left(\mathbf{m i n}^{-\mathbf{1}}\right)$ & & 0.9792 &
\end{tabular}

The second-best kinetic model was the Korsmeyer-Peppas model where the diffusion dissolution index $(n)$ gives the information about the diffusion and the erosion of the matrix. The values of the $n$ are increased from $n=0.182$ (PLA) to $n=0.223$ (PLGA65), which is referred to for the diffusion-controlled quasi Fickian drug release. Furthermore, it is important to note that the value of the diffusion dissolution index is lower than 0.42 . This is caused by the high polydispersity of the particles (because they are lyophilized) and the very low degradation of the polymers [32]. Presumably, the Case II relaxation contribution from the Peppas-Sahlin model will be low by these effects.

During the slow degradation of the PLA/PLGA carrier, the drug diffuses with difficulty from the core of the particles. The measured and calculated results clearly stated that the released drug originates from the surface region of the particles. Based on this, we could calculate the approximate quantity of the TP in the core of the particles after $7 \mathrm{~h}: 65.0 \%$ (PLA), 71.7\% (PLGA75) and 80.2\% (PLGA65) from the encapsulated mass of the TP; therefore, a significant amount of the active ingredient can be encapsulated inside the particles.

\section{Conclusions}

In the work presented here, the successful encapsulation of the hydrophobic $\alpha$-Tocopherol, one of the determinative natural forms of vitamin E, was carried out using the PLA, PLGA75 and PLGA65 biocompatible polymer carriers by increasing hydrophilicity. To the best of our knowledge, we first proved the formation of well-defined nanosized TP-core PLA/PLGA-shell structured nanocomposites. Optimization of the experimental conditions, such as optimal concentration of drug, polymer carrier and stabilizing PLUR non-ionic surfactant, resulted in the formation of core-shell NPs within the diameter range of 200-220 nm. For the PLA-based system 14.7\% of drug loading was achieved, where most of the TP molecules are encapsulated in the core $(65 \%)$, while the remaining part of the active ingredient is located on the surface of the polymer shell. By replacing the hydrophobic PLA to PLGA copolymers, both the drug loading (PLGA75: 16\%, PLGA65: 18\%) as well the EE\% can be increased (PLA/TP: 69.1\%; PLGA75/TP: 75.7\%; PLGA65/TP: 87.7\%). Furthermore, the PLGA-based composites contain $71.7 \%$ and $80.2 \%$ of the encapsulated TP in the core. Considering the slower precipitation ability of the PLGA copolymers in contrast to the PLA and the active ingredient, the higher 
encapsulation efficiency can be explored. Besides the preparation and the characterization of the composites, the drug release was also studied. The dissolution curves clearly show that depending on the polymer, more than $65-80 \%$ of the TP is contained in the composites after $7 \mathrm{~h}$. In the first half an hour, the dissolution of the drug occurs relatively quickly, but after that, measurable slow dissolution was observed. Moreover, we found that the active substance is released slowly with decreasing lactide part (PLA, 35.0\%; PLGA75, 28.3\%; PLGA65, 19.8\%) in $7 \mathrm{~h}$. Thanks to the biocompatibility, cost-effectivity and tuneable hydrophilic properties, the PLA/PLGA polymers are potential candidates for controlled drug release and for the encapsulation of hydrophobic TP or similar sized and structured molecules in core-shell nanosized particles.

Supplementary Materials: The following are available online at http://www.mdpi.com/1999-4923/11/7/0357/s1. Figure S1: UV spectra of TP in 1,4-dioxane at different concentrations, Figure S2: The turbidity of TP (a) and PLA (b) in PLUR solution at $25^{\circ} \mathrm{C}$ in aqueous medium $\left(\mathrm{c}_{\mathrm{TP}}=0.25 \mathrm{mg} \cdot \mathrm{mL}^{-1}, \mathrm{c}_{\mathrm{PLA}}=0.25 \mathrm{mg} \cdot \mathrm{mL}^{-1}\right)$, Figure S3: IR spectra of the TP- free (a) and TP- loaded (b) PLGA75 NPs $\left(\mathrm{c}_{\mathrm{TP}}=2.5 \mathrm{mg} \cdot \mathrm{mL}^{-1}, \mathrm{c}_{\mathrm{PLA}}=10 \mathrm{mg} \cdot \mathrm{mL}^{-1}, \mathrm{c}_{\mathrm{PLUR}}=0.1 \mathrm{mg} \cdot \mathrm{mL}^{-1}\right)$, Figure S4: IR spectra of the TP- free (a) and TP- loaded (b) PLGA65 NPs $\left(\mathrm{c}_{\mathrm{TP}}=2.5 \mathrm{mg} \cdot \mathrm{mL}^{-1}, \mathrm{c}_{\mathrm{PLA}}=10 \mathrm{mg} \cdot \mathrm{mL}^{-1}\right.$, $C_{\text {PLUR }}=0.1 \mathrm{mg} \cdot \mathrm{mL}^{-1}$ ), Figure S5: Release profiles and different kinetic models-predicted (First Order model (a), Weibull model (b)) release curves of TP from PLA and PLGA NPs in PBS solution ( $\mathrm{pH}=7.4,0.9 w / w \% \mathrm{NaCl})$.

Author Contributions: Conceptualization, E.C.; methodology, N.V.; investigation, N.V. and Á.T. and V.H.; data curation, Á.T.; writing—original draft preparation, E.C.; writing—review and editing, V.H.; supervision, E.C.

Funding: University of Szeged Open Access Fund.

Acknowledgments: The research was supported by the National Research, Development and Innovation Office-NKFIH through the project GINOP-2.3.2-15-2016-00060. V.H. acknowledges the Premium Post Doctorate Research Program of the Hungarian Academy of Sciences for the financial support. This paper was supported by the János Bolyai Research Scholarship of the Hungarian Academy of Sciences (E. Csapó). The Ministry of Human Capacities, Hungary grant TUDFO/47138-1/2019-ITM is acknowledged.

Conflicts of Interest: The authors declare no conflict of interest.

\section{References}

1. Kumari, A.; Yadav, S.K.; Yadav, S.C. Biodegradable polymeric nanoparticles based drug delivery systems. Colloids Surf. B Biointerfaces 2010, 75, 1-18. [CrossRef] [PubMed]

2. Nair, L.S.; Laurencin, C.T. Biodegradable polymers as biomaterials. Prog. Polym. Sci. 2007, 32, 762-798. [CrossRef]

3. Rancan, F.; Papakostas, D.; Hadam, S.; Hackbarth, S.; Delair, T.; Primard, C.; Verrier, B.; Sterry, W.; Blume-Peytavi, U.; Vogt, A. Investigation of Polylactic Acid (PLA) Nanoparticles as Drug Delivery Systems for Local Dermatotherapy. Pharm. Res. 2009, 26, 2027-2036. [CrossRef] [PubMed]

4. Chanphai, P.; Vesper, A.R.; Bariyanga, J.; Bérubé, G.; Tajmir-Riahi, H.A. Review on the delivery of steroids by carrier proteins. J. Photochem. Photobiol. B Biol. 2016, 161, 184-191. [CrossRef] [PubMed]

5. Janovák, L.; Turcsányi, Á.; Bozó, É.; Deák, Á.; Mérai, L.; Sebők, D.; Juhász, Á.; Csapó, E.; Abdelghafour, M.M.; Farkas, E.; et al. Preparation of novel tissue acidosis-responsive chitosan drug nanoparticles: Characterization and in vitro release properties of Ca2+ channel blocker nimodipine drug molecules. Eur. J. Pharm. Sci. 2018, 123, 79-88. [CrossRef] [PubMed]

6. Sarmento, B.; Ferreira, D.; Veiga, F.; Ribeiro, A. Characterization of insulin-loaded alginate nanoparticles produced by ionotropic pre-gelation through DSC and FTIR studies. Carbohydr. Polym. 2006, 66, 1-7. [CrossRef]

7. Csapó, E.; Szokolai, H.; Juhász, Á.; Varga, N.; Janovák, L.; Dékány, I. Cross-linked and hydrophobized hyaluronic acid-based controlled drug release systems. Carbohydr. Polym. 2018, 195, 99-106. [CrossRef] [PubMed]

8. Lassalle, V.; Ferreira, M.L. PLA Nano- and Microparticles for Drug Delivery: An Overview of the Methods of Preparation. Macromol. Biosci. 2007, 7, 767-783. [CrossRef]

9. Jia, W.J.; Gu, Y.C.; Gou, M.L.; Dai, M.; Li, X.Y.; Kan, B.; Yang, J.L.; Song, Q.F.; Wei, Y.Q.; Qian, Z.Y. Preparation of Biodegradable Polycaprolactone/Poly(ethylene glycol)/Polycaprolactone (PCEC) Nanoparticles. Drug Deliv. 2008, 15, 409-416. [CrossRef] 
10. Zhang, Y.; Zhuo, R. Synthesis and drug release behavior of poly(trimethylene carbonate)-poly(ethylene glycol)-poly(trimethylene carbonate) nanoparticles. Biomaterials 2005, 26, 2089-2094. [CrossRef]

11. Leach, J.B.; Schmidt, C.E. Characterization of protein release from photocrosslinkable hyaluronic acid-polyethylene glycol hydrogel tissue engineering scaffolds. Biomaterials 2005, 26, 125-135. [CrossRef] [PubMed]

12. Jiang, X.; Xin, H.; Ren, Q.; Gu, J.; Zhu, L.; Du, F.; Feng, C.; Xie, Y.; Sha, X.; Fang, X. Nanoparticles of 2-deoxy-d-glucose functionalized poly(ethylene glycol)-co-poly(trimethylene carbonate) for dual-targeted drug delivery in glioma treatment. Biomaterials 2014, 35, 518-529. [CrossRef] [PubMed]

13. Varga, N.; Hornok, V.; Janovák, L.; Dékány, I.; Csapó, E. The effect of synthesis conditions and tunable hydrophilicity on the drug encapsulation capability of PLA and PLGA nanoparticles. Colloids Surf. B Biointerfaces 2019, 176, 212-218. [CrossRef] [PubMed]

14. Kiss, É.; Gyulai, G.; Pénzes, C.B.; Idei, M.; Horváti, K.; Bacsa, B.; Bősze, S. Tuneable surface modification of PLGA nanoparticles carrying new antitubercular drug candidate. Colloids Surf. A Physicochem. Eng. Asp. 2014, 458, 178-186. [CrossRef]

15. Duse, L.; Agel, M.R.; Pinnapireddy, S.R.; Schäfer, J.; Selo, M.A.; Ehrhardt, C.; Bakowsky, U. Photodynamic Therapy of Ovarian Carcinoma Cells with Curcumin-Loaded Biodegradable Polymeric Nanoparticles. Pharmaceutics 2019, 11, 282. [CrossRef] [PubMed]

16. Molina, I.; Li, S.; Martinez, M.B.; Vert, M. Protein release from physically crosslinked hydrogels of the PLA/PEO/PLA triblock copolymer-type. Biomaterials 2001, 22, 363-369. [CrossRef]

17. Hu, Y.; Jiang, X.; Ding, Y.; Zhang, L.; Yang, C.; Zhang, J.; Chen, J.; Yang, Y. Preparation and drug release behaviors of nimodipine-loaded poly(caprolactone)-poly(ethylene oxide)-polylactide amphiphilic copolymer nanoparticles. Biomaterials 2003, 24, 2395-2404. [CrossRef]

18. Duhem, N.; Danhier, F.; Préat, V. Vitamin E-based nanomedicines for anti-cancer drug delivery. J. Control. Release 2014, 182, 33-44. [CrossRef]

19. Zigoneanu, I.G.; Astete, C.E.; Sabliov, C.M. Nanoparticles with entrapped $\alpha$-tocopherol: Synthesis, characterization, and controlled release. Nanotechnology 2008, 19, 105606. [CrossRef]

20. Alqahtani, S.; Simon, L.; Astete, C.E.; Alayoubi, A.; Sylvester, P.W.; Nazzal, S.; Shen, Y.; Xu, Z.; Kaddoumi, A.; Sabliov, C.M. Cellular uptake, antioxidant and antiproliferative activity of entrapped $\alpha$-tocopherol and $\gamma$-tocotrienol in poly(lactic-co-glycolic) acid (PLGA) and chitosan covered PLGA nanoparticles (PLGA-Chi). J. Colloid Interface Sci. 2015, 445, 243-251. [CrossRef]

21. Astete, C.E.; Dolliver, D.; Whaley, M.; Khachatryan, L.; Sabliov, C.M. Antioxidant Poly(lactic-co-glycolic) Acid Nanoparticles Made with $\alpha$-Tocopherol-Ascorbic Acid Surfactant. ACS Nano 2011, 5, 9313-9325. [CrossRef] [PubMed]

22. Murugeshu, A.; Astete, C.; Leonardi, C.; Morgan, T.; Sabliov, C.M. Chitosan/PLGA particles for controlled release of $\alpha$-tocopherol in the GI tract via oral administration. Nanomedicine 2011, 6, 1513-1528. [CrossRef] [PubMed]

23. Simon, L.C.; Stout, R.W.; Sabliov, C. Bioavailability of Orally Delivered Alpha-Tocopherol by Poly(Lactic-Co-Glycolic) Acid (PLGA) Nanoparticles and Chitosan Covered PLGA Nanoparticles in F344 Rats. Nanobiomedicine 2016, 3, 8. [CrossRef] [PubMed]

24. Benkő, M.; Varga, N.; Sebők, D.; Bohus, G.; Juhász, Á.; Dékány, I. Bovine serum albumin-sodium alkyl sulfates bioconjugates as drug delivery systems. Colloids Surf. B Biointerfaces 2015, 130, 126-132. [CrossRef] [PubMed]

25. Dash, S.; Murthy, P.N.; Nath, L.; Chowdhury, P. Kinetic modeling on drug release from controlled drug delivery systems. Acta Pol. Pharm. 2010, 67, 217-223.

26. Costa, P.; Sousa Lobo, J.M. Modeling and comparison of dissolution profiles. Eur. J. Pharm. Sci. 2001, 13, 123-133. [CrossRef]

27. Peppas, N.A.; Sahlin, J.J. A simple equation for the description of solute release. III. Coupling of diffusion and relaxation. Int. J. Pharm. 1989, 57, 169-172. [CrossRef]

28. Silva, M.E.S.R.; Freitas, R.F.S.; Sousa, R.G. Synthesis, Characterization, and Study of PLGA Copolymer in Vitro Degradation. J. Biomater. Nanobiotechnol. 2015, 6, 8-19. [CrossRef]

29. Che Man, Y.B.; Ammawath, W.; Mirghani, M.E.S. Determining $\alpha$-tocopherol in refined bleached and deodorized palm olein by Fourier transform infrared spectroscopy. Food Chem. 2005, 90, 323-327. [CrossRef] 
30. Gyulai, G.; Magyar, A.; Rohonczy, J.; Orosz, J.; Yamasaki, M.; Bosze, S.; Kiss, E. Preparation and characterization of cationic Pluronic for surface modification and functionalization of polymeric drug delivery nanoparticles. Express Polym. Lett. 2016, 10, 216-226. [CrossRef]

31. Bouchemal, K.; Agnely, F.; Koffi, A.; Ponchel, G. A concise analysis of the effect of temperature and propanediol-1, 2 on Pluronic F127 micellization using isothermal titration microcalorimetry. J. Colloid Interface Sci. 2009, 338, 169-176. [CrossRef] [PubMed]

32. Ritger, P.L.; Peppas, N.A. A simple equation for description of solute release I. Fickian and non-fickian release from non-swellable devices in the form of slabs, spheres, cylinders or discs. J. Control. Release 1987, 5, 23-36. [CrossRef]

(C) 2019 by the authors. Licensee MDPI, Basel, Switzerland. This article is an open access article distributed under the terms and conditions of the Creative Commons Attribution (CC BY) license (http://creativecommons.org/licenses/by/4.0/). 